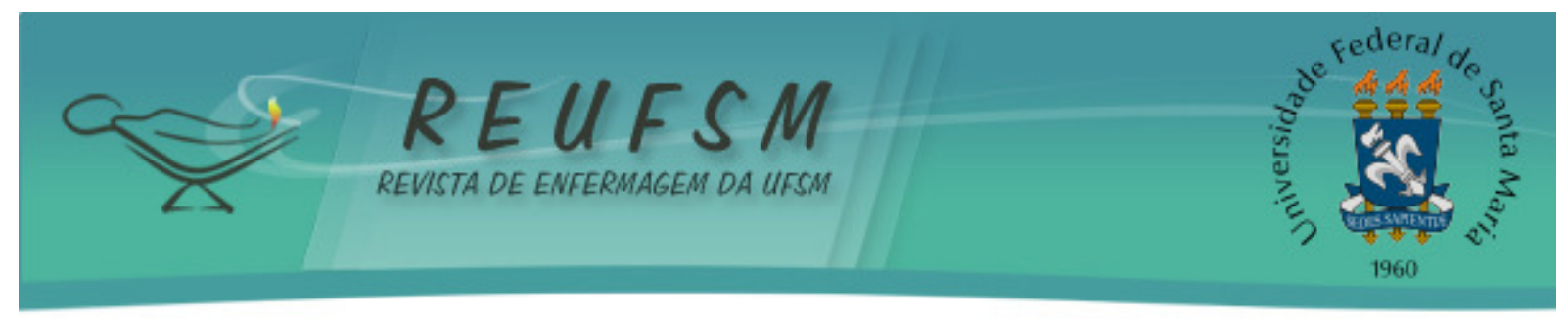

EDITORIAL

\title{
MORRER EM CASA, NO HOSPITAL OU EM ESTABELECIMENTOS MÉDICO- SOCIAIS? - OU SOBRE AS REDEFINIÇÕES DOS ESPAÇOS PARA O FINAL DE VIDA
}

\section{TO DIE AT HOME, IN THE HOSPITAL OR IN SOCIAL-MEDICAL ESTABLISHMENTS? - OR ABOUT REDEFINITIONS OF PLACES FOR THE END OF LIFE}

\begin{abstract}
¿MORIR EN CASA, EN EL HOSPITAL O EN ESTABLECIMIENTOS MÉDICOSOCIALES? - O SOBRE LAS REDEFINICIONES DE LOS ESPACIOS PARA EL FINAL DE LA VIDA
\end{abstract}

Franciele Roberta Cordeiro ${ }^{1}$

Doi: $10.5902 / 2179769229021$

O domicílio é o local onde, culturalmente, ocorrem processos relacionais entre os diferentes membros de uma família. ${ }^{1}$ A partir dos anos 2000, os discursos sobre o retorno ao domicílio para o tratamento de pessoas com doenças crônicas e de pessoas em final de vida ganharam força em diversos países, tendo em vista o esgotamento do hospital para atender as demandas de saúde da população. ${ }^{2}$ No contexto do final da vida, no Brasil, a atenção domiciliar tem sido proposta como uma possibilidade e alternativa às hospitalizações. Ela se caracteriza por ações que visam à promoção, à reabilitação e à paliação da saúde no ambiente domiciliar. Como nem sempre esses serviços são acessíveis ou as famílias não possuem estrutura para acolher uma pessoa em final de vida no domicílio, as instituições de longa permanência para idosos tem sido uma alternativa.

Instituições desse tipo são comuns em países que experienciam o envelhecimento há mais tempo, como por exemplo, a França. Esses estabelecimentos, entendidos como médicosociais, devido sua dupla função, utilizam equipamentos, medicações e estruturas que fazem parte de um mercado produzido para atender as demandas oriundas da dependência, que incluem aquelas experimentadas no processo de morrer.

Nesse sentido, aponta-se os estabelecimentos médico-sociais como uma mescla de elementos do hospital com a personalização do domicílio. Trata-se de estratégia onerosa, que

\footnotetext{
${ }^{1}$ Professora Adjunta na Faculdade de Enfermagem da Universidade Federal de Pelotas (UFPel). Enfermeira pela Universidade Federal de Santa Maria (UFSM). Doutora e mestre em Enfermagem pela Universidade Federal do Rio Grande do Sul (UFRGS). Especialista em Cuidados Paliativos pela Université Grenoble Alpes (França). Integrante do Núcleo de Condições Crônicas e suas Interfaces (NUCCRIN- UFPel) e do Laboratório de Estudos e Pesquisas Rede de Cuidados Paliativos (LEP-RCP - UFPel), Pelotas, RS, Brasil. E-mail: franciele.cordeiro@ufpel.edu.br
} 


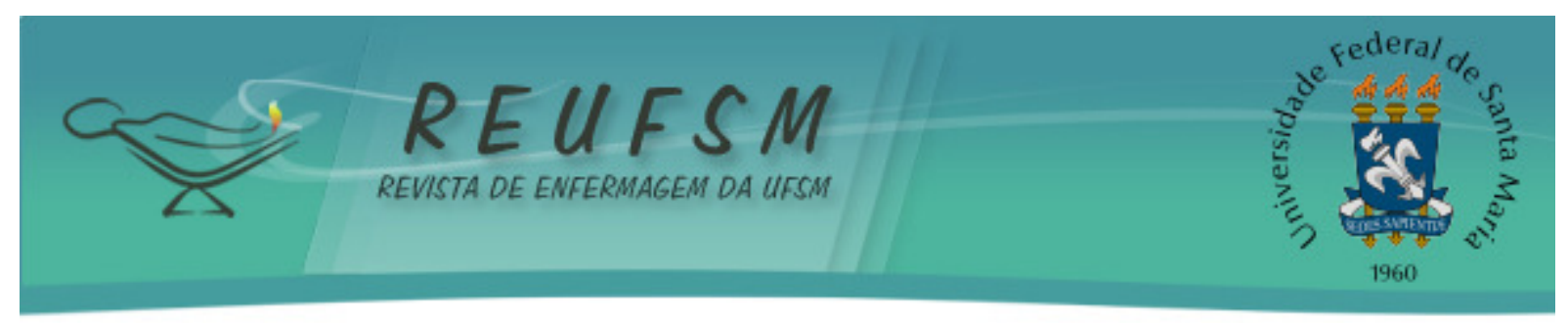

tenta ser uma opção para o final de vida, mas que nem sempre atende às expectativas e solicitações dos doentes e das famílias. Isso porque, quando a morte se aproxima, tanto doentes como familiares ainda acreditam ser os hospitais, especialmente os serviços de Cuidados Paliativos, os estabelecimentos que podem proporcionar o alívio de sintomas refratários, como a dor e a dispneia.

Segundo o relatório do Observatório Nacional do Final da Vida da França sobre as condições em que morrem as pessoas idosas naquele país, na última semana de vida em estabelecimentos médico-sociais, $75 \%$ das pessoas têm a presença frequente dos familiares. Por outro lado, quando os doentes entram na fase de agonia, em que ocorre piora do quadro clínico, as instituições tendem a encaminhar as pessoas para morrer no hospital. Mesmo com o aparato tecnológico e com os recursos materiais de que dispõem, tanto as equipes quanto os familiares parecem não saber lidar com os momentos que antecedem a morte. ${ }^{3-4}$

Dessa forma, identifica-se um importante problema para os sistemas de saúde, a partir do qual é preciso criar estratégias para conduzir o final da vida. As pessoas vivem mais e, esse tempo também foi acrescido aos últimos dias de vida. Esse fenômeno tem sido identificado em países como a França e também no Brasil. Nesse último país, o processo de envelhecimento tem acontecido de forma rápida, exigindo novas condutas do Estado para atender pessoas que também vivem cada vez mais solitárias. Os estabelecimentos médico-sociais como espaços para o final de vida tem sido uma alternativa que passa a ser incorporada também pela população brasileira, ainda que timidamente. Resta saber como será organizado seu acesso e qual será a assistência prestada às pessoas em final de vida nestas instituições.

\section{REFERENCIAS}

1. Mccallum C, Bustamante V. Parentesco, gênero e individuação no cotidiano da casa em um bairro popular de salvador da Bahia. Etnográfica. 2012 [acesso em 2017 aug 5];16(2):22146. Disponivel em: https://etnografica.revues.org/1476.

2. Cordeiro, FR. O retorno ao domicílio em cuidados paliativos: interface dos cenários brasileiro e francês [tese]. Porto Alegre: Universidade Federal do Rio Grande do Sul; 2017. 262 f.

3. Briot MTL. Fin de vie des personnes âgées. Jusqu'à la Mort Accompagner la Vie, Grenoble, 2015 ;119(1):97-108.

4. Observatoire National de la Fin de Vie. Fin de vie, un premier état des lieux: rapport 2011. Paris, Observatoire National de la Fin de Vie ; 2011 [acesso em 2014 nov 23]. Disponivel em: https://sites.google.com/site/observatoirenationalfindevie/. 